\title{
Hospitalization Outcomes in Pneumocystis Pneumonia Inpatient Population: A Comparison between HIV and Non-HIV Patients
}

Sorabh Datta ${ }^{1}$, Shanan Mahal ${ }^{2}$, Virendrasinh Ravat ${ }^{3}$, Bipin Saroha ${ }^{4}$, Ehinor E. Isidahome ${ }^{5}$, Priya Patel

1. Department of Emergency Medicine, New York Presbyterian Queens, Flushing, USA 2. Department of Internal Medicine, Providence Hospital, Washington DC, USA 3. Department of Infectious Disease, Clinical Infectious Disease Specialist, Las Vegas, USA 4. Department of Internal Medicine, University of Chicago Medical Center, Chicago, USA 5. Department of Internal Medicine, Saint Joseph Hospital, London, USA 6. Department of Psychiatry, Windsor University School of Medicine, Philadelphia, USA

Corresponding author: Priya Patel, priya.patel1810@gmail.com

\section{Abstract}

\section{Objective}

To evaluate the difference in hospitalization outcomes, including morbidity and mortality among patients admitted for Pneumocystis pneumonia (PCP) with human immunodeficiency virus (HIV) and non-HIV condition.

\section{Methods}

A case-control study was done using the Healthcare Cost and Utilization Project (HCUP) Nationwide Inpatient Sample (NIS) data. We identified PCP and HIV as the primary and secondary diagnosis using ICD9-CM diagnosis codes. We used the multinomial logistic regression model to generate odds ratios (OR).

\section{Results}

A total number of 1250 PCP patients were enrolled in this retrospective analysis. PCP patients with HIV had eight times higher odds of non-elective admission based on emergency condition $(\mathrm{OR}=7.873, \mathrm{P}<.001)$ compared to non-HIV patients. PCP patients with HIV had eight times higher odds of longer hospitalization of more than eight days $(\mathrm{OR}=8.687, \mathrm{P}<.001)$ compared to non-HIV patients. HIV patients with PCP had five times higher odds of severe morbidity or extreme loss of body function $(\mathrm{OR}=5.277, \mathrm{P}<.001)$. PCP patients with HIV had 22 times higher likelihood of in-hospital mortality $(\mathrm{OR}=21.845, \mathrm{P}<.001)$ compared to nonHIV patients.

\section{Conclusion}

Received 06/13/2018 Review began 07/20/2018 Review ended 07/25/2018 Published 08/01/2018

\section{() Copyright 2018}

Datta et al. This is an open access article distributed under the terms of the Creative Commons Attribution License CC-BY 3.0., which permits unrestricted use, distribution, and reproduction in any medium, provided the original author and source are credited.
PCP patients with HIV have a higher risk of severe morbidity and in-hospital mortality as compared to nonHIV patients. More attention needs to be paid to the elderly population that is at a higher risk of PCP with HIV. We need additional research and studies to direct the development of clinical care models for aiming early diagnosis and treatment of HIV in PCP patients.

Categories: Internal Medicine, HIV/AIDS, Pulmonology

Keywords: pcp, pneumocystis pneumonia, mortality, morbidity, national inpatient sample, hospitalization, outcomes, hiv

\section{Introduction}

Pneumocystis pneumonia (PCP) is an opportunistic infection of the lung caused by the fungus Pneumocystis jirovecii [1]. PCP is commonly seen in immunocompromised individuals [2].

PCP is also a common opportunistic infection among people living with human immunodeficiency virus/acquired immunodeficiency syndrome (HIV/AIDS) in developing countries [3]. HIV-infected patients with a low CD4 count are at the highest risk of PCP. Others at substantial risk include hematopoietic cell and solid organ transplant recipients, those with cancer (particularly hematologic malignancies), and those receiving glucocorticoids, chemotherapeutic agents, and other immunosuppressive medications.

The incidence of PCP is increasing as the number of people receiving immunosuppressive medications continues to grow [4]. The incidence of PCP appears to vary by underlying condition, as in hematologic malignancies it is $32.5 \%, 18.2 \%$ in solid tumors, $14.9 \%$ in inflammatory diseases, and $12.3 \%$ in solid organ transplant [5]. In patients with malignancies, the reported rates vary with underlying disease and immunosuppressive regimen, it is $22 \%-45 \%$ in children with acute lymphoblastic leukemia without prophylaxis, which decreases to $0 \%$ with prophylaxis, $25 \%$ among patients with Hodgkin lymphoma without 
prophylaxis and $1.3 \%$ among patients with primary or metastatic central nervous system (CNS) tumor with available prophylaxis $[4,6]$. Also, there was $1 \%$ to $2 \%$ incidence in patients with rheumatologic disorders who were not taking prophylaxis treatment, especially those patients which were receiving immunosuppressive medications [4]. The mortality rate is about $30-50 \%$ in patients without HIV [7, 8] and it is around $10-12 \%$ in patients with HIV [9].

The main objective of this study is to analyze the differences in hospitalization outcomes in terms of hospital stay and cost, morbidity and mortality in PCP patients with HIV versus with non-HIV conditions.

\section{Materials And Methods}

\section{Data source}

The Agency for Healthcare Research and Quality (AHRQ) sponsors the Healthcare Cost and Utilization Project (HCUP) databases that are specifically designed to determine and identify patterns in utilization and cost across the United States hospitals [10]. The Nationwide Inpatient Sample (NIS) database is the inpatient database available in the United States. Any information about the patients, physicians, hospitals, and hospital identifiers is de-identified, to protect the privacy of the individual. This data contains some nonclinical information of patient's demographic data, hospital characteristics, and inpatient charges, and the clinical-related information includes primary, and secondary diagnosis, disposition or discharge status and the length of inpatient stay.

\section{Variables of interest}

Based on the International Classification of Diseases, 9th Edition, Clinical Modifications (ICD-9-CM) diagnosis codes, we identified the controls that included patients with a primary diagnosis of PCP during hospital admission and a secondary diagnosis of the non-HIV conditions as mentioned in Table 1 . The cases were identified with a primary diagnosis of PCP and secondary diagnosis of HIV. PCP was identified using diagnosis code 136.3, and HIV was identified using ICD-9-CM diagnosis codes 042, 0420-0422, 0429-0433, 0439, 0440, 0449 079.53, 279.10, 279.19, 795.71, 795.8 or V08. To measure the differences in hospitalization outcomes in PCP patients with HIV versus PCP with the non-HIV condition, the outcome variables of interest included the severity of illness, inpatient length of stay, inpatient total charges, disposition of patient and in-hospital mortality [11]. 


\section{Cureus}

\section{Disease}

Hodgkin's

Lymphoma

Non-Hodgkin's

Lymphoma

Common Variable

Immunodeficiency

Familia

Hemophagocytic

lymphohistiocytosis

X-Linked

agammaglobulinemia

Pancytopenia

$284.19,284.09,284.11,284.12$

Chronic

Granulomatous

disease

Wiskott-Aldrich

Syndrome

Neutropenia

Chronic lymphocytic

leukemia

Complement

Deficiency Asplenia

Multiple Myeloma

ICD-9-CM Diagnosis Code V10.60-V10.63, V10.69

279.06, 279.00, 279.05, 279.3

288.4, D76.1

279.04, D80.0

$288.1,686.1$

204.10

279.8
201.00-201.18, 201.20-201.28, 201.40-201.48, 201.50-201.58, 201.60-201.68, 201.70-201.78, 201.90-201.98, V10.72, 202.21-202.28, 202.70-202.78, 202.80-202.88, 202.90-202.98, V10.71, V10.79

200.00-200.08, 200.10-200.18, 200.20-200.28, 200.30-200.38, 200.40-200.48, 200.50-200.58, 200.60-200.68, 200.70$200.78,200.80-200.88,202.00-202.08,202.10-202.18,202.20$

202.40-202.48, 203.1, 203.10-203.12, 204.0, 204.00-204.02, 204.1, 204.10- 204.12, 204.2, 204.20-204.22, 204.8, 204.80204.82, 204.9, 204.90-204.92, 205.0, 205.00-205.02, 205.1, 205.10-205.12, 205.2, 205.20-205.22, 205.3, 205.30-205.32, 205.8, 205.80-205.82, 205.9, 205.90-205.92, 206.0, 206.00-206.02, 206.1, 206.10-20612, 206.2, 206.20-206.22, 206.8, 206.80-206.82, 206.9, 206.90-206.92, 207.0, 207.00-207.02, 207.1, 207.10-207.12, 207.2, 207.20-207.22, 207.8, 207.80207.82, 208.0, 208.00-208.02, 208.1, 208.10-208.12, 208.2, 208.20-208.22, 208.8, 208.80-208.82, 208.9, 208.90-208.92,

$279.12,279.3,279.10,279.2,279.19$

$780.60,288.00-288.04,288.09,776.7,289.53$

203.0, 203.00-203.02, 203.8, 203.80-203.82

TABLE 1: ICD-9-CM diagnosis codes for non-HIV conditions.

ICD-9-CM: International Classification of Diseases, 9th Revision, Clinical Modification

\section{Case and control selection}

Cases were selected from the NIS dataset with a primary diagnosis of PCP, the secondary diagnosis of HIV and age $>18$ years. Controls included the patients with a primary diagnosis of PCP, a secondary diagnosis of non-HIV condition as mentioned in Table 1 and were matched with the cases for age, gender and race.

\section{Statistical analysis}

A cross-sectional study was conducted using the HCUP NIS data from 2012 to 2014. An exploratory data analysis using cross tabulation was performed on the NIS database, thereby targeting the PCP patients with HIV versus with non-HIV conditions. Pearson's Chi-square test and independent sample T-test were used for categorical data and continuous data, respectively. Multinomial logistic regression model for differences in hospital outcomes was used to calculate adjusted odds ratio (aOR) and was adjusted for age, gender, and the race. All the tests were two-sided and a p-value $<.05$ was used as a referent for a statistical significance test result. The analysis was conducted using Statistical Package for the Social Sciences (IBM, Armonk, NY) [12]. The study database does not contain any patient identification and so we were not required to take the Institution Review Board (IRB) permission for this study.

\section{Results}




\section{Cureus}

\section{Demographic characteristics}

We analyzed a total number of 1250 PCP patients in this study from which 895 cases had HIV and 355 controls had non-HIV conditions. PCP with HIV was seen more in older patients aged 51-60 years $(\mathrm{N}=230$; $25.7 \%)$, and was equally common in $41-50$ years $(\mathrm{N}=155 ; 17.3 \%)$ and $61-70$ years' age $(\mathrm{N}=160 ; 17.9 \%)$ patients. PCP is seen in a low proportion of young patients with HIV (7.8\% in 18-30 years and $9.5 \%$ in 31 40 years' age). Majority of the HIV patients were males $(\mathrm{N}=525 ; 58.7 \%)$ and Caucasians $(\mathrm{N}=450 ; 53.3 \%)$. The demographic distribution of the sample population is mentioned in Table 2.

\begin{tabular}{|c|c|c|c|c|}
\hline \multirow{2}{*}{ Variable } & \multicolumn{2}{|c|}{ Non-HIV } & \multicolumn{2}{|l|}{ HIV } \\
\hline & $\mathrm{N}$ & $\%$ & $\mathrm{~N}$ & $\%$ \\
\hline \multicolumn{5}{|l|}{ Age } \\
\hline $18-30$ years & 5 & 1.4 & 70 & 7.8 \\
\hline $31-40$ years & 20 & 5.6 & 85 & 9.5 \\
\hline $41-50$ years & 60 & 16.9 & 155 & 17.3 \\
\hline $51-60$ years & 85 & 23.9 & 230 & 25.7 \\
\hline $61-70$ years & 85 & 23.9 & 160 & 17.9 \\
\hline$>70$ years & 100 & 28.2 & 195 & 21.8 \\
\hline \multicolumn{5}{|l|}{ Gender } \\
\hline Male & 225 & 63.4 & 525 & 58.7 \\
\hline Female & 130 & 36.6 & 370 & 41.3 \\
\hline \multicolumn{5}{|l|}{ Race } \\
\hline Caucasian & 275 & 77.5 & 450 & 53.3 \\
\hline African American & 65 & 18.3 & 210 & 24.9 \\
\hline Hispanic & 10 & 2.8 & 100 & 11.8 \\
\hline Asian/Pacific Islander & 5 & 1.4 & 30 & 3.6 \\
\hline Native American & 0 & 0 & 5 & .6 \\
\hline Other & 0 & 0 & 50 & 5.9 \\
\hline
\end{tabular}

\section{TABLE 2: Demographic distribution in PCP patients by HIV.}

\section{Differences in hospitalization outcomes}

About 93.9\% ( $N=840$ ) PCP patients with HIV were admitted based on an emergency condition or nonelective basis, whereas $91.5 \%(\mathrm{~N}=325)$ were admitted on an elective basis. PCP patients with HIV had eight times higher odds of non-elective admission based on emergency condition $(\mathrm{OR}=7.873, \mathrm{p}<.001)$ compared to non-HIV patients. Also, HIV patients had higher odds of being transferred from another health facility $(\mathrm{OR}=13.646, \mathrm{p}<.001)$ followed by acute care hospital $(\mathrm{OR}=10.701, \mathrm{p}<.001)$ compared to non-HIV patients.

The mean inpatient length of stay per admission for PCP patients with HIV was 11.78 days which was marginally higher than that seen in non-HIV patients (10.1 days). The median inpatient length of stay per admission for all PCP patients was eight days and 48.6\% (N = 435) HIV patients were hospitalized for more than eight days as compared to $47.9 \%$ ( $\mathrm{N}=170$ ) non-HIV patients, though the result was not statistically significant $(\mathrm{p}=.819)$. However, HIV patients had eight times higher odds of longer hospitalization of more than eight days $(\mathrm{OR}=8.687, \mathrm{p}<.001)$ compared to non-HIV patients with PCP. The median hospitalization cost per admission for PCP was $\$ 59,923$. PCP patients with HIV had ten times likelihood of higher hospitalization charges of more than $\$ 59,923(\mathrm{OR}=10.229$, $\mathrm{p}<.001$ ) compared to non-HIV patients.

HIV patients with PCP had five times higher odds of severe morbidity or major loss of body function (OR = $5.851, \mathrm{p}<.001)$ compared to non-HIV patients. Also, $18.4 \%(\mathrm{~N}=165)$ PCP patients with HIV died during 


\section{Cureus}

hospitalization compared to $11.3 \%(\mathrm{~N}=40)$ patients with non-HIV conditions $(\mathrm{P}=.002)$. HIV patients with PCP had 22 times higher odds of in-hospital mortality $(\mathrm{OR}=21.845, \mathrm{p}<.001)$ compared to non-HIV patients. Differences in hospitalization outcomes are shown in Table 3.

\begin{tabular}{|c|c|c|c|c|c|}
\hline \multirow{2}{*}{ Variable } & \multicolumn{2}{|c|}{ Non-HIV } & \multicolumn{2}{|l|}{ HIV } & \multirow{2}{*}{$\mathbf{P}$} \\
\hline & $\mathrm{N}$ & $\%$ & $\mathrm{~N}$ & $\%$ & \\
\hline \multicolumn{6}{|l|}{ Admission Type } \\
\hline Non-elective & 325 & 91.5 & 840 & 93.9 & \multirow{2}{*}{.144} \\
\hline Elective & 30 & 8.5 & 55 & 6.1 & \\
\hline \multicolumn{6}{|l|}{ Transfer from facility } \\
\hline Acute care hospital & 15 & 4.2 & 50 & 5.6 & \multirow{2}{*}{.579} \\
\hline Another health facility & 5 & 1.4 & 15 & 1.7 & \\
\hline \multicolumn{6}{|l|}{ Severity of illness or morbidity } \\
\hline Moderate loss of body function & 0 & 0 & 95 & 10.6 & \multirow{2}{*}{$<.001$} \\
\hline Major loss of body function & 355 & 100 & 800 & 89.4 & \\
\hline \multicolumn{6}{|l|}{ Inpatient length of stay per admission } \\
\hline Mean & \multicolumn{2}{|c|}{10.1 days } & \multicolumn{2}{|c|}{11.78 days } & .008 \\
\hline$>8$ days (median) & 170 & 47.9 & 435 & 48.6 & .819 \\
\hline \multicolumn{6}{|l|}{ Inpatient total cost per admission } \\
\hline Mean & \multicolumn{2}{|c|}{$\$ 93,305$} & \multicolumn{2}{|c|}{$\$ 106,752$} & .104 \\
\hline$>\$ 59,923$ (median) & 165 & 46.5 & 450 & 50.3 & .226 \\
\hline \multicolumn{6}{|l|}{ In-hospital mortality } \\
\hline Deaths during hospitalization & 40 & 11.3 & 165 & 18.4 & .002 \\
\hline \multicolumn{6}{|l|}{ Disposition of patient } \\
\hline Routine & 210 & 59.2 & 440 & 49.2 & \multirow{5}{*}{.012} \\
\hline Short-term hospital & 5 & 1.4 & 20 & 2.2 & \\
\hline Skilled nursing/intermediate nursing facility & 60 & 16.9 & 160 & 17.9 & \\
\hline Home health care & 35 & 9.9 & 90 & 10.1 & \\
\hline Against medical advice & 5 & 1.4 & 20 & 2.2 & \\
\hline
\end{tabular}

\section{TABLE 3: Hospital outcomes in PCP patients by HIV.}

Significant $p \leq 0.05$ at $95 \%$ confidence interval.

PCP: Pneumocystis carinii pneumonia

A higher proportion of HIV patients $(\mathrm{N}=160 ; 17.9 \%)$ were discharged to skilled nursing facility or intermediate nursing facility (SNF/INF), and so they had very high odds of discharge to SNF/INF (OR = $23.238, \mathrm{p}<.001)$ compared to non-HIV patients ( $\mathrm{N}=60 ; 16.9 \%)$. Also, HIV patients had a higher likelihood of disposition to the short-term hospital $(\mathrm{OR}=22.230, \mathrm{p}<.001)$ compared to non-HIV patients. Association of adverse hospitalization outcomes in HIV patients during admission for PCP is mentioned in Table 4. 


\section{Cureus}

\begin{tabular}{|c|c|c|c|c|}
\hline \multirow{2}{*}{ Variable } & \multirow{2}{*}{ Odds Ratio } & \multicolumn{2}{|c|}{ 95\% Confidence Interval } & \multirow{2}{*}{$\mathbf{P}$} \\
\hline & & Lower Bound & Upper Bound & \\
\hline Transfer from acute care hospital & 10.701 & 4.908 & 23.333 & $<.001$ \\
\hline Transfer from another health facility & 13.646 & 4.261 & 43.705 & $<.001$ \\
\hline Non-elective/Emergency admission & 7.873 & 4.742 & 13.071 & $<.001$ \\
\hline Inpatient length of stay $>8$ days & 8.687 & 5.041 & 14.971 & $<.001$ \\
\hline Inpatient total cost $>\$ 59,923$ & 10.229 & 5.851 & 17.884 & $<.001$ \\
\hline Major loss of body function/morbidity & 5.277 & 3.144 & 8.858 & $<.001$ \\
\hline In-hospital mortality & 21.845 & 11.012 & 43.337 & $<.001$ \\
\hline Disposition to SNF/INF & 23.238 & 11.107 & 48.617 & $<.001$ \\
\hline Disposition to short-term hospital & 22.230 & 7.083 & 69.770 & $<. c$ \\
\hline
\end{tabular}

\section{TABLE 4: Association of adverse hospital outcomes in PCP with HIV patients.}

Significant $\mathrm{p} \leq .05$ at $95 \%$ confidence interval, Odds Ratio were adjusted for age, gender and race.

PCP: Pneumocystis carinii pneumonia; SNF: Skilled nursing facility; INF: Intermediate nursing facility

\section{Discussion}

In this study, among older patients above 60 years' age, PCP was more prevalent in non-HIV patients as compared to HIV patients, which could be due to the fact that older patients were less likely to have acquired HIV via intravenous drug use or homosexual contact as compared to patients below 60 years. Also, older patients were more likely to have comorbid diseases (non-HIV conditions) like cancer, end-stage renal disease and ageing $[13,14]$. Among 41-50 years and 51-60 years aged patients, PCP was more common in HIV patients. This is due to an increase in the number of HIV diagnoses among males aged 18-60 years which was driven by an increase in HIV diagnoses among young homosexual men [15]. Also based on the previous studies, HIV is more prevalent in the age group 18-60 years as compared to >60 years age patients [16]. In our study, the majority of the PCP patients with HIV were males as compared to females, it could be due to the fact that females may be at higher epidemiologic and socio-behavioral risk for HIV. Also, they lack early counseling, diagnosis and treatment as compared to males [17]. Males, however, were better informed about the use of Antiretrovirals than females and also due to the fact that women had a lower socioeconomic status or to some biological differences as compared to men [18].

PCP patients with HIV had much higher admission rates based on emergency condition compared to nonHIV patients in this study. Majority of the PCP patients with HIV are coming with acute symptoms like an acute respiratory failure, which is a complication of PCP in $5 \%-30 \%$ of cases and is associated with a high risk of in-hospital death [19]. PCP is a major cause of life-threatening pneumonia in the immunocompromised host, therefore they are more presented as an emergency case in PCP patients with HIV [20]. In the previous study, the pooled overall mortality for non-HIV patients with PCP was significantly higher than previously reported mortality rate in HIV patients. There are several possible explanations for the poorer outcomes in non-HIV patients with PCP such as the majority of these patients were older and had the more underlying cardiopulmonary disease than HIV-positive patients with PCP. The duration of symptoms onset to the beginning of PCP treatment was much longer in non-HIV patients. Also, HIV patients with PCP were benefited from adjunctive corticosteroid therapy, but there is no proof that adjunctive corticosteroid is beneficial to non-HIV patients. This suggests that non-HIV PCP may not benefit from the advances in the management of PCP [21]. In the current study, PCP patients with HIV were having a longer inpatient length of stay as compared to non-HIV patients. This fact can be supported by previous studies where the duration of symptoms in HIV-infected patients was consistently longer than for HIVnegative patients [22-24].

In our study, morbidity and mortality are much higher in HIV patients with PCP as compared to non-HIV patients with PCP. And it can be supported with past studies which show that due to the use of PCP prophylaxis the incidence of PCP is low, but that PCP is still a common disease in patients unaware of their HIV infection. On the other hand, a study also suggests that CNS disease is the major immediate cause of death in patients on PCP prophylaxis [25]. Based on various studies we also found that Highly Active Antiretroviral Treatment (HAART) is independently and statistically significantly associated with decreased mortality and morbidity rates in PCP patients [26]. 
To identify the significant strength of our study, a nationally represented dataset was selected with the inclusion of a uniform collection of data through ICD-9-CM codes. To our knowledge, this is the first study to report the impact of HIV on PCP patients regarding hospital outcomes, morbidity, and mortality. The NIS dataset is subject to a minimal reporting bias. Also, all the information from this dataset is coded independently of the practitioner, which makes it a dependable source.

Limitations of our study include the lack of patient-level data from the NIS dataset, which is needed to make accurate clinical associations. As an administrative database, the NIS dataset has this limitation. Besides, such retrospective studies are always subject to selection bias, which might be highlighted by the moderate sensitivity of diagnostic codes for PCP, HIV and non-HIV conditions. After considering all the potential limitations with overall comparisons, the NIS database presents an unparalleled population-based perspective on disease associations with systematic and temporal factors providing a rationale for further in-depth studies.

\section{Conclusions}

Among PCP patients with HIV versus without HIV, we observed variation in demographic and hospital characteristics and significant differences in the risk of in-hospital mortality. Men with PCP were more prevalent in the non-HIV group as compared to female patients with PCP which were more prevalent in the HIV group. Also, PCP patients with HIV have greater all-cause mortality as compared to patients without HIV. From this study, we also see that there is a rise in PCP among women with the comorbid HIV which needs to be addressed with educational training regarding primary and secondary prevention of HIV. To decrease the HIV-related mortality and morbidity in these patients, the future direction for PCP management should include strategies for early diagnosis and treatment of HIV.

\section{Additional Information}

\section{Disclosures}

Human subjects: Consent was obtained by all participants in this study. Animal subjects: All authors have confirmed that this study did not involve animal subjects or tissue. Conflicts of interest: In compliance with the ICMJE uniform disclosure form, all authors declare the following: Payment/services info: All authors have declared that no financial support was received from any organization for the submitted work. Financial relationships: All authors have declared that they have no financial relationships at present or within the previous three years with any organizations that might have an interest in the submitted work. Other relationships: All authors have declared that there are no other relationships or activities that could appear to have influenced the submitted work.

\section{Acknowledgements}

We would also like to show our gratitude to our research project supervisor- Rikinkumar S Patel MD, MPH (Griffin Memorial Hospital, OK) for sharing his pearls of wisdom with us during the course of this study and conducting the statistical analysis for the nationwide data.

\section{References}

1. Edman JC, Kovacs JA, Masur H, Santi DV, Elwood HJ, Sogin ML: Ribosomal RNA sequence shows Pneumocystis carinii to be a member of the fungi. Nature. 1988, 334:519-522. 10.1038/334519a0

2. Nageswaran A, Kinghorn GR, Shen RN, Priestley JF, Kyi TT: Hospital service utilization by HIV/AIDS patients and their management cost in a provincial genitourinary medicine department. Int J STD AIDS. 1995, 6:336-344. 10.1177/095646249500600506

3. De Armas Rodríguez Y, Wissmann G, Müller AL, et al.: Pneumocystis jirovecii pneumonia in developing countries. Parasite. 2011, 18:219-228. 10.1051/parasite/2011183219

4. Sepkowitz KA: Opportunistic infections in patients with and patients without acquired immunodeficiency syndrome. Clin Infect Dis. 2002, 34:1098-1107. 10.1086/339548

5. Fillatre P, Decaux O, Jouneau S, et al.: Incidence of Pneumocystis jiroveci pneumonia among groups at risk in HIV-negative patients. Am J Med. 2014, 127:1242.e11-1242.e17. 10.1016/j.amjmed.2014.07.010

6. Waks AG, Tolaney SM, Galar A, et al.: Pneumocystis jiroveci pneumonia (PCP) in patients receiving neoadjuvant and adjuvant anthracycline-based chemotherapy for breast cancer: incidence and risk factors. Breast Cancer Res Treat. 2015, 154:359-367. 10.1007/s10549-015-3573-2

7. Roux A, Gonzalez F, Roux M, et al.: Update on pulmonary Pneumocystis jirovecii infection in non-HIV patients. Med Mal Infect. 2014, 44:185-198. 10.1016/j.medmal.2014.01.007

8. Yale SH, Limper AH: Pneumocystis carinii pneumonia in patients without acquired immunodeficiency syndrome: associated illness and prior corticosteroid therapy. Mayo Clin Proc. 1996, 71:5-13.

9. Roux A, Canet E, Valade S, et al.: Pneumocystis jirovecii pneumonia in patients with or without AIDS, France. Emerg Infect Dis. 2014, 20:1490-1497. 10.3201/eid2009.131668

10. HCUP NIS Database Documentation. Healthcare Cost and Utilization Project (HCUP) . (2018). Accessed: June 9, 2018: https://www.hcup-us.ahrq.gov/db/nation/nis/nisdbdocumentation.jsp.

11. NIS Description of Data Elements. Healthcare Cost and Utilization Project (HCUP) . (2017). Accessed: June 9, 2018: https://www.hcup-us.ahrq.gov/db/nation/nis/nisdde.jsp.

12. IBM SPSS Statistics for Windows. (2015). Accessed: June 9, 2018: https://www.ibm.com/products/spssstatistics. 
13. Saltzman RL, Peterson PK: Immunodeficiency of the elderly. Rev Infect Dis. 1987, 9:1127-1139. 10.1093/clinids/9.6.1127

14. Keitz SA, Bastian LA, Bennett CL, Oddone EZ, DeHovitz JA, Weinstein RA: AIDS-related Pneumocystis carinii pneumonia in older patients. J Gen Intern Med. 1996, 11:591-596. 10.1007/BF02599026

15. Rangel MC, Gavin L, Reed C, Fowler MG, Lee LM: Epidemiology of HIV and AIDS among adolescents and young adults in the United States. J Adolesc Health. 2006, 39:156-163. 10.1016/j.jadohealth.2006.02.011

16. U.S. Statistics. (2017). Accessed: June 9, 2018: https://www.hiv.gov/hiv-basics/overview/data-andtrends/statistics.

17. West BS, Pouget ER, Tempalski B, Cooper HL, Hall HI, Hu X, Friedman SR: Female and male differences in AIDS diagnosis rates among people who inject drugs in large U.S. metro areas from 1993 to 2007. Ann Epidemiol. 2015, 25:218-225. 10.1016/j.annepidem.2015.01.006

18. Mosha F, Muchunguzi V, Matee M, et al.: Gender differences in HIV disease progression and treatment outcomes among HIV patients one year after starting antiretroviral treatment (ART) in Dar es Salaam, Tanzania. BMC Public Health. 2013, 13:38. 10.1186/1471-2458-13-38

19. Zahar JR, Robin M, Azoulay E, Fieux F, Nitenberg G, Schlemmer B: Pneumocystis carinii pneumonia in critically ill patients with malignancy: a descriptive study. Clin Infect Dis. 2002, 35:929-934. 10.1086/342338

20. Walzer PD, Evans HE, Copas AJ, Edwards SG, Grant AD, Miller RF: Early predictors of mortality from Pneumocystis jirovecii pneumonia in HIV-infected patients: 1985-2006. Clin Infect Dis. 2008, 46:625-633. $10.1086 / 526778$

21. Liu Y, Su L, Jiang SJ, Qu H: Risk factors for mortality from pneumocystis carinii pneumonia (PCP) in nonHIV patients: a meta-analysis. Oncotarget. 2017, 8:59729-59739. 10.18632/oncotarget.19927

22. Ewig S, Bauer T, Schneider C, Pickenhain A, Pizzulli L, Loos U, Lüderitz B: Clinical characteristics and outcome of Pneumocystis carinii pneumonia in HIV-infected and otherwise immunosuppressed patients. Eur Respir J. 1995, 8:1548-1553.

23. Kovacs JA, Hiemenz JW, Macher AM, et al.: Pneumocystis carinii pneumonia: a comparison between patients with the acquired immunodeficiency syndrome and patients with other immunodeficiencies. Ann Intern Med. 1984, 100:663-671. 10.7326/0003-4819-100-5-663

24. Nuesch R, Bellini C, Zimmerli W: Pneumocystis carinii pneumonia in human immunodeficiency virus (HIV)positive and HIV-negative immunocompromised patients. Clin Infect Dis. 1999, 29:1519-1523. $10.1086 / 313534$

25. Hentzen BT, Schreij G: Patterns of morbidity and mortality in AIDS patients on Pneumocystis carinii prophylaxis who died during hospital admission: a report of 50 diseased patients. Neth J Med. 1996, 49:101105.

26. Murphy EL, Collier AC, Kalish LA, et al.: Highly active antiretroviral therapy decreases mortality and morbidity in patients with advanced HIV disease. Ann Intern Med. 2001, 135:17-26. 10.7326/0003-4819135-1-200107030-00005 